\title{
Assessment of the Finnish wolf population combines DNA captures, citizen observations and mortality data using a Bayesian state-space model
}

\author{
Samu Mäntyniemi ${ }^{*}$, Inari Helle ${ }^{1}$ and Ilpo Kojola ${ }^{2}$ \\ $1^{*}$ Natural Resources Institute Finland, Latokartanonkaari 9, \\ Helsinki, 00790, Finland. \\ ${ }^{2}$ Natural Resources Institute Finland, Ounasjoentie 6, Rovaniemi, \\ 96200, Finland.
}

*Corresponding author(s). E-mail(s): samu.mantyniemi@luke.fi; Contributing authors: inari.helle@luke.fi; ilpo.kojola@luke.fi;

\begin{abstract}
Assessment of the Finnish wolf population relies on multiple sources of information. This paper describes how Bayesian inference is used to pool the information contained in different kind of data sets (point observations, non-invasive genetics, known mortalities) for the estimation of the number of territories occupied by family packs and pairs. The output of the assessment model is a joint probability distribution, which describes current knowledge about the number of wolves within each territory. The joint distribution can be used to derive probability distributions for the total number of wolves in all territories and for the pack status within each territory. Most of the data set comprises of both voluntary-provided point observations and DNA samples provided by volunteers and research personnel. The new method reduces the role of expert judgement in the assessment process, providing increased transparency and repeatability.
\end{abstract}

Keywords: Markov chain Monte Carlo,Hierarchical modelling,Population dynamics 




December 22, 2021. The copyright holder for this preprint (which was not certified by peer

review) is the author/funder. All rights reserved. No reuse allowed without permission.

\section{$2 \quad$ Assessment of the Finnish wolf population}

\section{Introduction}

An important prerequisite for effective population management is reliable population monitoring, since population counts are imperative for several activities like setting hunting quotas and assessing the conservation status of a species. However, large carnivores pose a challenge for population monitoring, because they typically inhabit large remote areas with low densities (Herfindal et al, 2005; Kindberg et al, 2011; Mattisson et al, 2013), for which reason species observations often accumulate unevenly and with varying precision. Furthermore, voluntary-provided data are often used in monitoring of large carnivore populations (Kindberg et al, 2011; Bragina et al, 2015; Cretois et al, 2020). Thus, any population monitoring scheme focusing on large carnivores need to cope with varying levels of uncertainty.

The wolf (Canis lupus) has experienced major population collapses in its native range in Europe and North America due to human activities but is now recolonising many areas (Chapron et al, 2014; Ripple et al, 2014). This is the case also in Finland, where, due to intense hunting, the wolf population dropped drastically from approximately 1000 individuals to only some dozens in the second half of the 1800s (Mykrä et al, 2017). In the 1990s, the wolf reestablished a permanent population, after which the population has fluctuated but has been increasing since 2017, the latest population count (March 2021) being $32-38$ packs (90\% probability interval) and $18-25$ pairs (90\% probability interval) (Heikkinen et al, 2021).

The recolonization has resulted in conflicts, as the wolf causes damages to domestic animals, attacks hunting dogs and evokes fear in people (Marucco and Boitani, 2012; Flykt et al, 2013; Johansson et al, 2016; Olson et al, 2019; Tikkunen and Kojola, 2020; Bassi et al, 2021). Damage from wolves often generates displeasure and frustration and may fuel the illegal killing of wolves (Liberg et al, 2012; Pohja-Mykrä and Kurki, 2014; Suutarinen and Kojola, 2017; Liberg et al, 2020; Nowak et al, 2021). In Finland, the wolf is classified as endangered species Liukko et al (2019). Furthermore, outside the reindeer husbandry area, it is included in Annex IV of the EU's Habitats Directive, which requires strict protection of the species. However, the wolf is also a game species in Finland, and the latest management hunting season was implemented in 2015/2016 (Ministry of Agriculture and Forestry, 2019). Due to a more liberal culling policy, a few and only short-term territories exist in the reindeer husbandry region (Kojola et al, 2009; Heikkinen et al, 2021).

Given the complex situation and conflicting aims and views present in the society, it is evident that there is a strong need for reliable monitoring of the wolf population in Finland. The regular monitoring of the Finnish wolf population started in 1978, and today the monitoring is based on volunteer-provided point observations, non-invasive DNA samples collected by volunteers and wildlife professionals, information acquired from GPS-collared animals, and knowledge on known annual mortality (Kojola et al, 2009). Until recently, these data were used by experts to delineate the wolf territories, to estimate the number of individuals per territory, and by using the proportion of non-residents 


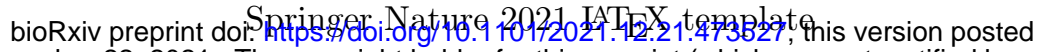
December 22, 2021. The copyright holder for this preprint (which was not certified by peer review) is the author/funder. All rights reserved. No reuse allowed without permission.

reported in the literature (Fuller et al, 2003)), to produce the final population estimate (Kojola et al, 2009). However, as this process is heavily expert-driven, the need for a method that integrates available knowledge in a more transparent and repeatable manner while explicitly expressing uncertainty has been recognized.

In this paper, we describe a new method we have developed to estimate the size of the Finnish wolf population annually. The method is based on Bayesian inference, which is well suited to the question at hand, as it enables efficient integration of multiple data sources and handles uncertainty explicitly. In recent years, Bayesian modelling has been applied to estimate wolf populations based on, for instance, sign surveys, howling sessions and multistate hierarchical site occupancy model (Jiménez et al, 2016), spatial DNA capturerecapture (Bischof et al, 2020), and on an individual-based model which uses the number of packs, reproductions and pairs as data (Chapron et al, 2016). In our approach, the starting point for the analysis is wolf territories delineated by experts as described by Kojola et al (2018). Our aim is to answer the question: Based on the data accumulated within each delineated wolf territory, what is the pack status and number of wolves per each territory, and consequently, what is the total number of wolves occupying the delineated territories in Finland, given the associated uncertainties?

The paper is structured as follows. First, we shortly describe the different information sources used in the Finnish wolf population assessment. Next, we present an overview of the model structure, followed by results based on the data set used in 2020 population assessment. We finish with a discussion about the strengths and weaknesses of the new method and propose directions for further improvement of the assessment model. Technical details of the model are described in Appendix A.

\section{Material and methods}

The Finnish wolf population assessment has two phases. In the first phase, potential territory areas are estimated by a panel of experts based on all the available information (clusters of point observations of packs and twosomes, GPS-locations of collared wolves; Kojola et al (2018)). In the second phase, territory specific data are used to infer the number of wolves occupying each territory using the Bayesian state-space model that we describe in this section (Fig 1). We exemplify the model by assessing the number of pairs, packs and total number of wolves in Finnish wolf territories in March 2020.

\subsection{Data}

The purpose of the state-space model is to pool information about the number of wolves within each territory from three different data sources: point observations, non-invasive DNA samples and reported mortality. The data collection protocol is described in detail in Kojola et al (2018). Hence, in the following, 


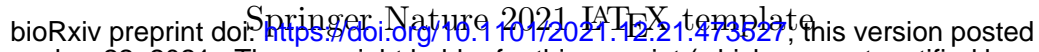

December 22, 2021. The copyright holder for this preprint (which was not certified by peer

review) is the author/funder. All rights reserved. No reuse allowed without permission.

we describe different data sets at the level which is sufficient to understand the modelling work in focus.

Point observations. Since 2009, point observations of wolves in Finland have been reported in the digital large carnivore monitoring system called Tassu ("the Paw"). The observations are recorded by approximately 2000 volunteer large carnivore contact persons, who have training in wolf ecology, behaviour, and paw print identification. For each observation, the type (sighting, track, prey kill site, or livestock depredation), date, location, the number and age status of animals, and front paw print dimensions are reported. These contact persons have their own local networks of trusted people, mostly hunters with an above average capability in species identification. Such a network is particularly relevant for sightings because sight observations cannot usually be validated afterwards in snow-free conditions. The observations are divided into observations made in autumn (from August to the end of December) and spring (January-February). All types of observations are treated similarly. Highest reported pack size, number of pair observations and number of observations concerning more than two wolves (packs) are used as model input.

The data set for March 2020 population assessment includes 2301 pair or pack observations gathered from 55 territories. The number of point observations reported per territory ranges from 1 to 149 . The median number of observations is 25. The highest reported pack size observation over all territories is 11 wolves.

DNA samples. Non-invasive DNA samples of wolves have been extensively collected for population monitoring purposes from 2016 onwards. Samples (mainly scats) are collected by volunteers (from November to February) and wildlife professionals (from November to March). The samples are used for identification of individuals and for kinship analyses. For this analysis, the samples are divided into observations made in autumn and in spring. Total number of successful DNA samples per territory and the number of different individuals found within these samples are used as model input.

The data set for March 2020 population assessment includes a total of 610 successful DNA samples, from which 190 different individuals were identified. The number of successful DNA samples per territory ranges from 0 to 43 . The maximum number of individuals found from a territory is 10 . Fifteen out of 55 territories have no DNA samples taken, whereas $50 \%$ of all territories have 10 or more successful samples.

Known mortality. In Finland, wolves that are hunted with a derogation or damage control licence, found dead or removed by police order, are sent to laboratory for autopsy. Regarding these individuals, several attributes are reported, including the location, date and cause of death, sex, and age. Also, tissue samples are are taken for DNA analysis. The number of individuals found dead within each territory is used as model input.

Previous expert estimates of pack sizes. Before the development of the model presented here, the number of individuals within each territory was 


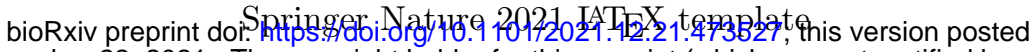
December 22, 2021. The copyright holder for this preprint (which was not certified by peer review) is the author/funder. All rights reserved. No reuse allowed without permission.



Fig. 1 The role of the Bayesian state-space model in the process of annual Finnish wolf population assessment. In the first phase, the territories are delineated by experts. In the second phase, different data are used to infer the number of wolves within each territory using the developed Bayesian state-space model. The results of the analysis are provided as probability distributions.

assessed by the expert panel based on all the data available from each territory. For each territory, minimum and maximum numbers of wolves were reported: these figures are used as model input in this analysis. These types of data are available from wolf population assessments conducted in 2018 and 2019. The data set contains estimated pack sizes for 88 cases.

Training data and assessment data. The data sets are divided into two parts, which are modelled separately. Training data consists of point observations and previous expert estimates of pack sizes from years prior to the target year (2018-2019). The purpose of this data is to provide information about the link between the point observations and expert assessments. Assessment data consists of point observations, DNA samples, and known mortality for each territory in the target year (2020).

\subsection{Model structure for wolf population assessment}

In this section, we provide an overview of the model structure and the modelling process. Detailed technical description of the model is given in Appendix A. The computer code and data necessary for replicating our example analysis are provided as online resource on publisher's website. 


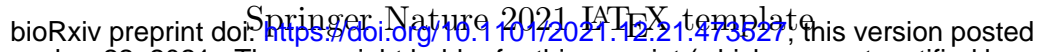
December 22, 2021. The copyright holder for this preprint (which was not certified by peer review) is the author/funder. All rights reserved. No reuse allowed without permission.

A prerequisite for the model is wolf territories inferred by the experts as described in Kojola et al (2018). We build our model on Bayesian statespace modelling approach, which incorporates both process variation and the uncertainty related to observations in a single model framework (Mäntyniemi et al, 2015). The process model is used to describe the survival process within each territory, and the observation models describe data generating processes related to point observations, DNA samples and known mortality. We assign prior distributions to the model parameters, and this prior knowledge is then updated with the information contained in the data, which results in a joint posterior probability distribution for model parameters. We estimated the joint posterior distribution by using Markov chain Monte Carlo (MCMC) sampling, implemented using the JAGS software (Plummer, 2003).

\subsubsection{Process model for survival within a territory}

The role of the survival model is to describe how the number of wolves within a territory can change over time. No reproduction takes place in wolf populations during the winter season; thus, we assume that the number of wolves in a territory can only decrease. Survival is assumed to vary between individual wolves around a common mean, which is not known exactly. This assumption creates a hierarchical structure, where information can flow between territories. Territories with more precise knowledge about the number of wolves in autumn and spring will provide more precise knowledge about the mean survival of wolves. This information is passed on to territories with less data in the form of prior information.

Prior distribution for the number of wolves in each territory has a similar hierarchical structure. Territories are assumed to be exchangeable a priori in terms of the number of wolves that they contain: we do not know which territory might have larger or smaller number of wolves than the others. This assumption means that the number of wolves in each territory can be thought of as a random draw from a hypothetical superpopulation of wolf territories: the probability of having, say, 6 wolves in a territory is equal to relative frequency of territories containing 6 individuals in a very large population of wolf territories. These relative frequencies are not known precisely but are assigned a prior distribution based on the distribution of wolf pack sizes in the past. This hierarchical structure provides another path by which territories can exchange information about the number of individuals: the prior distribution for each territory can be thought to be based on the distribution of pack sizes in other territories in the past and in the current year.

\subsubsection{Observation model for point observations from Tassu}

The role of the observation model for point observations is to describe the link between the true number of wolves and the point observations made by citizens within a territory. Prior knowledge about this link is available from earlier wolf population assessments, when the number of wolves within each territory was assessed by experts based on point observations, DNA data and 


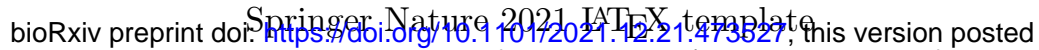
December 22, 2021. The copyright holder for this preprint (which was not certified by peer review) is the author/funder. All rights reserved. No reuse allowed without permission.

known mortality. Finding a statistical model between the expert estimates and point observations formalises the logic of expert interpretation of point observation data so that it can be automatically applied and included as a source of information in the state-space model.

Based on data from years 2018-2019, it was found that the expert estimated pack size is positively associated with the highest pack size reported by the volunteers. This relationship was modelled as a linear regression through origin (Fig 2). The expert estimated pack size was negatively associated with the proportion of pair observations of all observations concerning packs or pairs. This relationship was modelled with logistic regression (Fig 2).

Posterior distributions of linear and logistic regression parameters based on the fit to data from 2018 and 2019 contain the information about the link between the true number of wolves and point observations. When fitting the state-space model to target year data, these posteriors are used as prior distributions. These priors will be further updated when fitting the model to the target year data, provided that there are at least some territories from which lot of DNA data are available. This structure provides the third mechanism by which territories can exchange information through common parameters.

\subsubsection{Observation model for DNA samples}

Miller et al (2005) presented a model by which the size of a small population can be estimated based on DNA recaptures. The simplest form of the model assumes that all individuals have equal probability of being captured by DNA sampling. While this assumption is hardly true in the case of a wolf population spanning over very large area where the sampling effort is highly variable, it can be quite realistic within a single wolf territory, where all the pack members are well mixed and move around the same area. In this case, individual sampling histories are not needed. The number of successfully analysed samples and the number of different individuals found serve as sufficient statistics, on which the inference can be based.

We use the likelihood function derived by Miller et al (2005) as a link between the true number of wolves within a territory and DNA data. DNA samples collected during autumn and spring are assumed to be informative about the number of wolves in autumn. This accounts for the fact that individuals present in spring must have been present also in autumn. However, only samples collected in spring are assumed to be informative about the number of wolves in spring. This accounts for the fact that individuals found in autumn but not in spring may have died during the winter.

\subsubsection{Observation model for known mortality}

Wolves found dead within a territory provide a lower bound for the total number of wolves that may have died during the winter. At the same time, they also provide a lower bound for the total number of wolves that were initially alive in autumn. Known mortality is treated as a censored observation about the total number of dead wolves in a territory. This censoring creates 


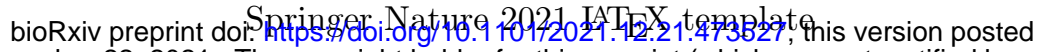
December 22, 2021. The copyright holder for this preprint (which was not certified by peer review) is the author/funder. All rights reserved. No reuse allowed without permission.
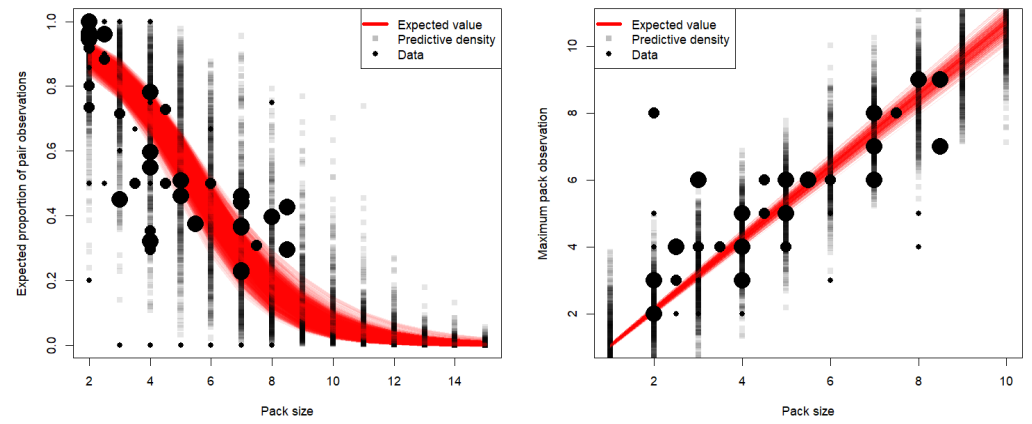

Fig. 2 Model fit for training data on the relationship between proportion of pair observations (left), observed maximum pack size (right) and estimated pack size (x-axis). Red lines are based on random draws of regression parameters from their joint posterior distribution. Grey squares are random draws from posterior predictive distribution, that will be used in population estimation in subsequent analysis. Black circles represent training data. Larger circle indicates larger amount of observations. The estimated pack size is plotted by using the mean estimate, when the estimated pack size was uncertain.

a likelihood contribution which can provide information about all the model parameters.

\section{Results}

\subsection{Training data}

We fitted the model first to training data from 2018 and 2019 and used the resulting posterior distribution of linear and logistic regression parameters as a prior when fitting the model to assessment data from 2020. Model fit for training data is shown in Fig 2, which also illustrates the predictive density of data values conditional on pack size. When estimating the pack size given an observed value, the likelihood function implied for the pack size can be visually seen from the graph by fixing a horizontal line at the observation. For example, proportion of pair observations equal to 0.4 would support pack sizes from 2 to 10 with most weight on 4 to 7 .

\subsection{Territories}

Fitting the model to assessment data produces a posterior distribution for the number of wolves in each territory. The posterior distributions were approximated using Markov chain Monte Carlo simulation, which means that summaries of the population can be derived simply by calculating the summary statistic for each iteration of the simulation and examining the distribution of the summary statistic.

Posterior distributions of the total number of wolves inhabiting the territories in autumn and spring are shown in Fig (3) together with the posterior distribution of the mean survival rate of all wolves. In addition to density and 


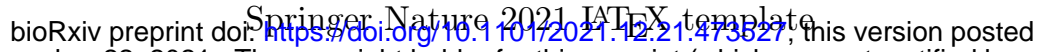
December 22, 2021. The copyright holder for this preprint (which was not certified by peer review) is the author/funder. All rights reserved. No reuse allowed without permission.



Number of individuals

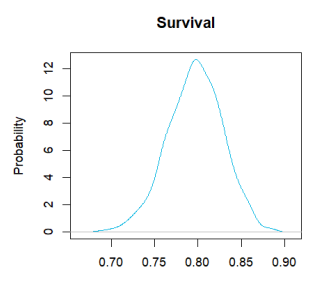

Survival rate

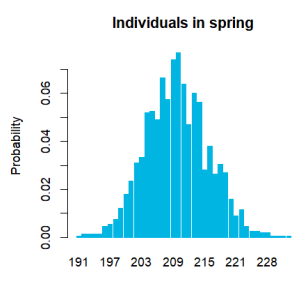

Number of individuals

Fig. 3 Marginal posterior distributions of the number of wolves in territories in autumn, survival rate from autumn to spring, and the number of wolves in territories in spring.

probability plots, posterior distributions can also be summarised with probability intervals that contain a specific amount of probability mass. For example, $90 \%$ probability interval for the number of individuals in autumn is [247,269]. The interval has the interpretation that the true value is thought to lie within this range with $90 \%$ probability. This is different from the concept of a confidence interval, which does not have interpretation as a formal statement of uncertainty about the variable of interest.

Posterior distributions of total numbers of packs, pairs, and empty (less than two wolves) territories are shown in Fig 4. These variables have negative posterior correlation because there are territories for which the classification is uncertain, but they can only belong to one class. Non-zero posterior correlation means that there is information about probable combinations of packs, pairs and empty territories that could not be seen directly from the marginal distributions of these variables. For example, combinations where both packs and pairs are either high or low are less probable than combinations where either one is high and the other one is low.

The functioning of the model is demonstrated with two territories, Halivaara (Fig 5) and Kallioluoma (Fig 6). Halivaara is an example of a territory with a high amount of data. It has total of 27 DNA samples collected throughout the season, from which 7 different individuals were identified. This provides strong information that places almost $100 \%$ probability for 7 wolves in autumn (Fig 5). 15 out of 27 DNA samples were collected in spring, from which 6 different individuals were identified. In addition, one individual was found dead, which further corroborates the inference that the number of wolves decreased during the winter (Fig 5). Because of high certainty exist that there were more than two wolves in the territory, the territory is classified as a pack with $100 \%$ probability (Fig 5).

Kallioluoma territory provides a contrasting example with no DNA samples (Fig 6). There were only 13 point observations reported on 2 or more wolves, and all point observations were made in autumn. One wolf was found dead during the winter. The posterior distribution of the number of wolves in autumn is wide, with the highest probability on 7 individuals (Fig 6). Highest reported point observation is 5 wolves, but the low proportion of pair observations (15\%) is typical for pack sizes larger than 5 (Fig 2). Hence, the 


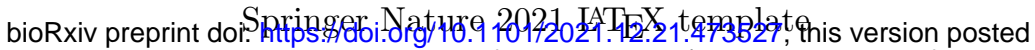

December 22, 2021. The copyright holder for this preprint (which was not certified by peer review) is the author/funder. All rights reserved. No reuse allowed without permission.
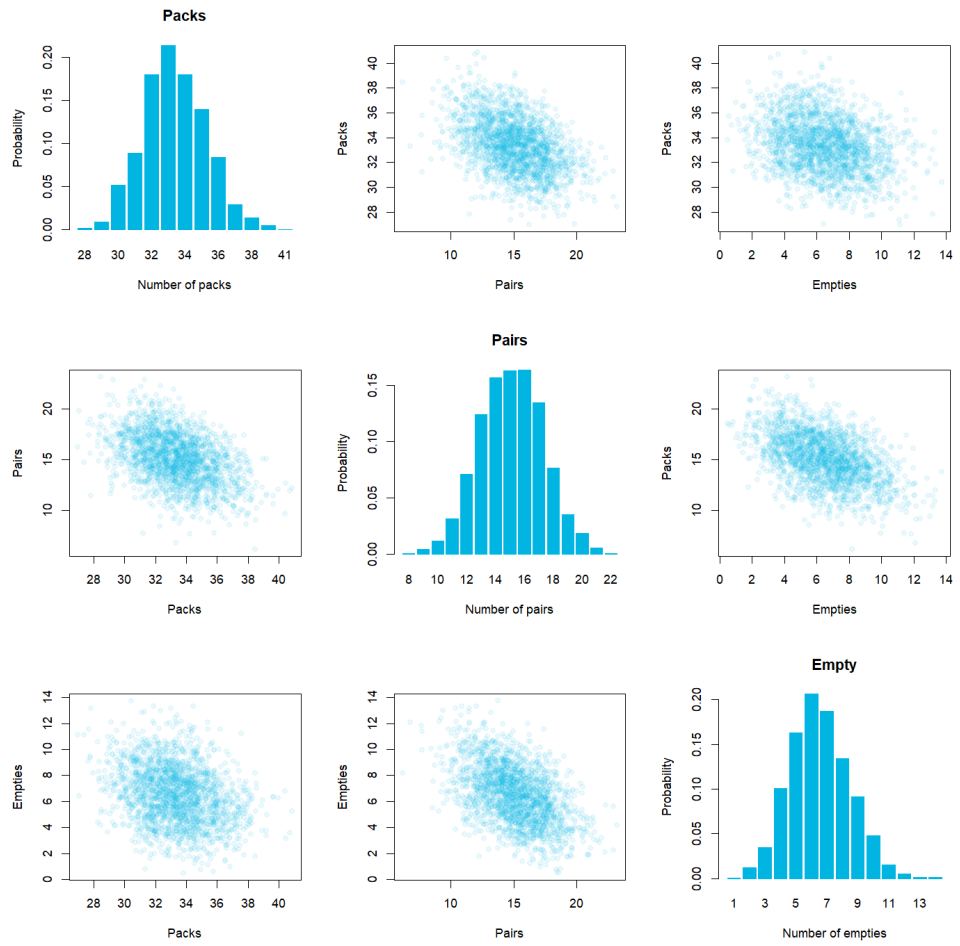

Fig. 4 Marginal posterior distributions and posterior correlations of the number of territories occupied by packs, the number of territories occupied by pairs, and the number of empty territories. Small random jitter with standard deviation $=1$ is added to the correlation plots in order to make the correlation more visible.
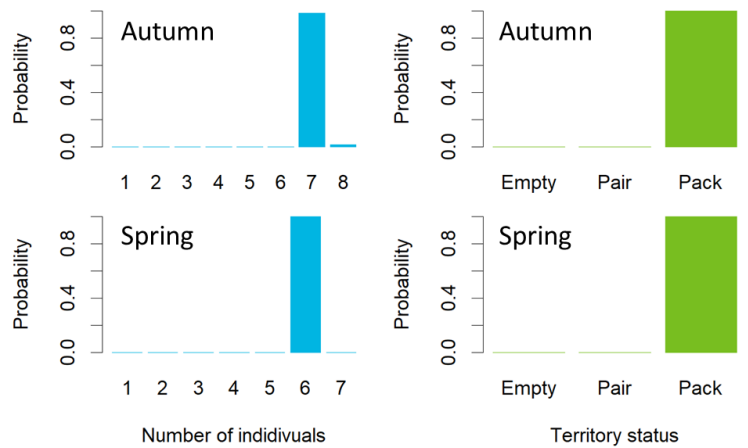

Fig. 5 Posterior distributions for the number of wolves (on the left) and territory status (on the right) in Halivaara territory in autumn (upper row) and in spring (lower row). 


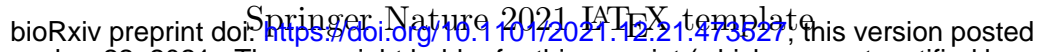
December 22, 2021. The copyright holder for this preprint (which was not certified by peer review) is the author/funder. All rights reserved. No reuse allowed without permission.
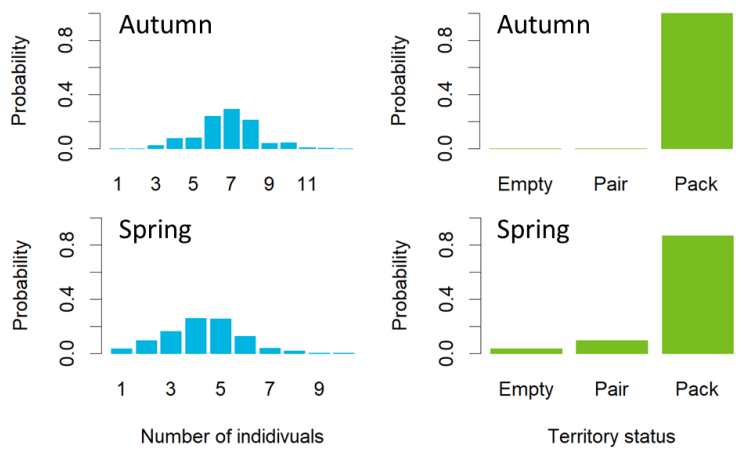

Fig. 6 Posterior distributions for the number of wolves (on the left) and territory status (on the right) in Kallioluoma territory in autumn (upper row) and in spring (lower row).

probability of such packs increases. The posterior distribution for the number of wolves in spring (Fig 6) is mostly based on estimated survival rate of wolves across all territories and on the number of wolves in autumn. This is backed up also by the one observed death. Kallioluoma territory serves also as an example of a territory for which the status is not certain. Occurrence of territories with uncertain status creates the negative correlation (Fig 4) between the total numbers of packs, pairs, and empty territories.

Data and results from all territories can be found from Online Resource 1.

\section{Discussion}

It is evident that the management of species like wolf, which evokes conflicts while being vulnerable to various human activities, requires reliable population assessment methods. It is also important to acknowledge the strong demand coming from various stakeholder groups in the society concerning the objectivity and transparency of population assessments and existing uncertainties. Further, focusing on a large carnivore which prefers forested areas and exhibits elusive behaviour, the assessment methods substantially benefit from as comprehensive use of all existing data as possible.

By adopting the Bayesian approach, we have been able to meet these demands. The method provides the result as a probability distribution, which enables intuitive communication of uncertainty. When the result is depicted as a probability distribution, the most probable number of wolves per territory is easily interpreted, but also the uncertainty related to the estimate is straightforward to perceive. By communicating results this way, also the less probable but still possible numbers of wolves are made visible. The hierarchical structure of the model allows for efficient use of all the available information, where data rich territories can share their information with data poor territories (Punt et al, 2011). 


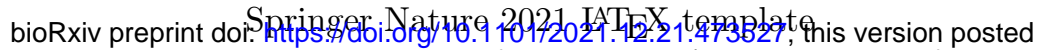
December 22, 2021. The copyright holder for this preprint (which was not certified by peer review) is the author/funder. All rights reserved. No reuse allowed without permission.

We have assumed that the size of a wolf pack would not increase during the winter compared to autumn. This assumption would become violated if a family pack would accept a dispersing wolf from another pack to join them. While this is in principle possible, it is believed to be too rare to significantly affect the population estimation.

Currently, the monitoring of wolf population in Finland is heavily dependent on point observations reported and DNA samples collected by volunteers. Both types of data are prone to changes in external circumstances. For instance, given the predicted climate change induced decrease in snow cover in Finland (Raisanen and Eklund, 2012), it is possible that the number of point observations made by volunteers will decline in the future. In most parts of Finland, the permanent snow season starts before December and the snow-off takes place in April or May, but the former has shifted to later and the latter to earlier dates (Luomaranta et al, 2019). As, for instance, in winters 2019/2020 and 2020/2021 approximately 55\% of the point observations between August and February were made in December, January and February (unpubl. data), the shortening of the snow season may be reflected in the number of observations. Similarly, the number of collected DNA samples can be highly dependent on the success of information campaigns and the general opinion on the usefulness of DNA collection for volunteers. Further, the number of DNA samples provided by volunteers from the same area may decline over time (refs). Such potential changes in available data does not affect the developed model as such but increase the uncertainty associated with the results. The effect is not symmetrical: As DNA provides more precise information on the number of wolves per territory than point observations, the potential decrease in available DNA samples would be more worrisome than the potential decrease in point observations. This emphasizes the need to maintain and reinforce further the collaboration between the research and volunteers.

Supplementary information. Full data sets, the computer code for running the analysis and detailed territory-specific results are available as Online Resource 1.

Acknowledgments. We wish to thank all volunteers and research personnel, who have contributed to the collection of data used in this study. We also wish to thank Mia Valtonen, Helena Johansson and the anonymous referees whose comments greatly improved the quality of this manuscript.

\section{Declarations}

Authors declare no conflict of interest.

If any of the sections are not relevant to your manuscript, please include the heading and write 'Not applicable' for that section. 




December 22, 2021. The copyright holder for this preprint (which was not certified by peer

review) is the author/funder. All rights reserved. No reuse allowed without permission.

\section{Appendix A Technical description of the Bayesian state-space model}

This appendix provides assumptions and mathematical details of the Bayesian state-space model used to estimate the number of wolves in Finnish wolf territories. List of symbols used for modelling the training data is presented in table A1. Symbols used for the state-space model are listed in tables A2 and A3.

\section{A.1 Training data}

The relationship between volunteer made observations and the estimated number of wolves in a territory was analysed from Finnish wolf population assessments conducted in 2018 and 2019. The data comprises of 88 territories from which the minimum and maximum estimates of the number of wolves in each territory in spring was available. The estimated pack size was found to be positively associated with the highest observed wolf pack size reported by the volunteers (Fig 2). This relationship was modelled as a linear regression through the origin as follows

$$
\begin{gathered}
m_{i}^{(S)} \sim N\left(\alpha^{(S)} N_{i}^{(S)}, \nu^{(S)} / \sqrt{x_{1, i}^{(S)}+x_{2, i}^{(S)}}\right) \\
m_{i}^{(A)} \sim N\left(\alpha^{(A)} N_{i}^{(A)}, \nu^{(A)} / \sqrt{\left.x_{1, i}^{(A)}+x_{2, i}^{(A)}\right)},\right.
\end{gathered}
$$

where $N_{i}^{(A)}=\left(1+u_{i}\right) N_{i}^{(S)}$. This structure reflects the fact that the number of wolves in the territory in autumn must have been larger or equal than the number of wolves in the following spring. The residual standard deviation is scaled by the square root of the total number of pack and pair observations made from the territory. This structure implies that the maximum observed pack size is more informative about the pack size when more data is reported from the territory.

The estimated pack size was found to be negatively associated with the proportion of pair observations from all pack or pair observations (Fig 2). This relationship was modelled using a random effects logistic regression in spring

$$
\begin{array}{r}
x_{i, 1}^{(S)} \sim \operatorname{Binomial}\left(x_{i, 1}^{(S)}+x_{i, 2}^{(S)}, \pi_{i}^{(S)}\right) \\
\operatorname{logit}\left(\pi_{i}^{(S)}\right)=\beta_{1}^{(S)}+\beta_{2}^{(S)}\left(N_{i}^{(S)}-2\right)+\sigma^{(S)} \epsilon_{i}^{(S)}
\end{array}
$$

and in autumn:

$$
\begin{array}{r}
x_{i, 1}^{(A)} \sim \operatorname{Binomial}\left(x_{i, 1}^{(A)}+x_{i, 2}^{(A)}, \pi_{i}^{(A)}\right) \\
\operatorname{logit}\left(\pi_{i}^{(A)}\right)=\beta_{1}^{(A)}+\beta_{2}^{(A)}\left(N_{i}^{(A)}-2\right)+\sigma^{(A)} \epsilon_{i}^{(A)} .
\end{array}
$$




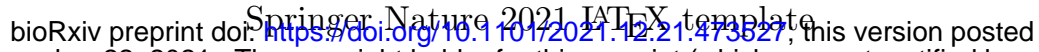
December 22, 2021. The copyright holder for this preprint (which was not certified by peer review) is the author/funder. All rights reserved. No reuse allowed without permission.

Assessment of the Finnish wolf population

\section{A.2 State-space model structure for wolf population assessment}

Territories are first inferred using expert judgement as in Kojola et al (2018). This model infers the number of individuals within each territory.

This is a Bayesian state-space model which describes the latent survival process in each territory. Different data sets are linked to the relevant states of the population using observation models.The following section explains each component in detail.

\section{A.2.1 Survival process}

Winter is divided into two phases: autumn and spring. Survival events of wolves are assumed to be independent of each other. The survival probability of all wolves across all territories is assumed to vary between individuals with mean survival probability $\theta$. As shown by Mäntyniemi et al (2015), these assumptions lead to binomial model for the number of wolves $\left(N_{t}^{(S)}\right)$ that survive from autumn $\left(N_{t}^{(A)}\right)$ to spring. We approximate the Binomial model with a scaled Beta distribution for computational convenience (Mäntyniemi et al, 2015):

$$
\begin{array}{r}
N_{t}^{(S)}=s_{t} N_{t}^{(A)} \\
s_{t} \sim \operatorname{Beta}\left(\left(N_{t}^{(A)}+1\right) \theta,\left(N_{t}^{(A)}+1\right)(1-\theta)\right),
\end{array}
$$

where $s_{t}$ is the proportion of wolves that survive to spring in territory $t$. Number of wolves in spring $\left(N_{t}^{(S)}\right)$ is rounded to nearest integer. If the number of wolves is zero after the rounding, then the number of wolves is set to one. This is for computational convenience, that does not affect the results, because only pack sizes of two or more are of interest.

Prior distribution for the number of wolves in a territory in autumn is defined using a hierarchical structure. Vector of proportions $\omega_{1}, \ldots, \omega_{15}$ describes the relative frequencies of different pack sizes in a hypothetical superpopulation of wolf packs, from which each pack is considered to be a random draw with replacement. The maximum possible wolf pack size is assumed to be 15. A Dirichlet prior is assigned to the vector of proportions

$$
\begin{gathered}
P\left(N_{t}^{(A)}=h \mid\left(\omega_{1}, \ldots, \omega_{15}\right)\right)=\omega_{h} \\
\omega_{1}, \ldots, \omega_{15} \sim \operatorname{Dirichlet}\left(\tau_{1}, \ldots, \tau_{15}\right) .
\end{gathered}
$$

where parameters $\tau_{1}, \ldots, \tau_{15}$ are fixed based on the distribution of pack sizes in earlier years. The hierarchical structure enables information to flow from territories with lots of data to territories with smaller number of observations.

The number of wolves that die during the winter is given by 


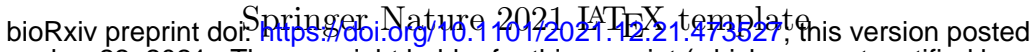

December 22, 2021. The copyright holder for this preprint (which was not certified by peer

review) is the author/funder. All rights reserved. No reuse allowed without permission.

$$
D_{t}=N_{t}^{(A)}-N_{t}^{(S)} .
$$

\section{Model for volunteer observations}

The observation model for the maximum observed pack size is identical to the observation model used for the training data:

$$
\begin{gathered}
m_{t}^{(S)} \sim N\left(\alpha^{(S)} N_{t}^{(S)}, \nu^{(S)} / \sqrt{x_{1, t}^{(S)}+x_{2, t}^{(S)}}\right) \\
m_{t}^{(A)} \sim N\left(\alpha^{(A)} N_{t}^{(A)}, \nu^{(A)} / \sqrt{x_{1, t}^{(A)}+x_{2, t}^{(A)}}\right) .
\end{gathered}
$$

Also, the observation model for the number of pair observations given the number of wolves in the territory and the number of pack observations is identical to the observation model used for the training data:

$$
\begin{array}{r}
x_{t, 1}^{(S)} \sim \operatorname{Binomial}\left(x_{t, 1}^{(S)}+x_{t, 2}^{(S)}, \pi_{i}^{(S)}\right) \\
\operatorname{logit}\left(\pi_{t}^{(S)}\right)=\beta_{1}^{(S)}+\beta_{2}^{(S)}\left(N_{t}^{(S)}-2\right)+\sigma^{(S)} \epsilon_{t}^{(S)} \\
x_{t, 1}^{(A)} \sim \operatorname{Binomial}\left(x_{t, 1}^{(A)}+x_{t, 2}^{(A)}, \pi_{t}^{(A)}\right) \\
\operatorname{logit}\left(\pi_{t}^{(A)}\right)=\beta_{1}^{(A)}+\beta_{2}^{(A)}\left(N_{t}^{(A)}-2\right)+\sigma^{(A)} \epsilon_{t}^{(A)} .
\end{array}
$$

Prior distribution for the parameter vector

$$
\left(\alpha^{(S)}, \nu^{(S)}, \alpha^{(A)}, \nu^{(A)}, \beta_{1}^{(S)}, \beta_{2}^{(S)}, \sigma^{(S)}, \beta_{1}^{(A)}, \beta_{2}^{(A)}, \sigma^{(A)}\right)
$$

is a multivariate normal distribution with mean vector and covariance matrix equal to posterior mean vector and covariance matrix obtained by analysing the training data from 2018 and 2019 wolf population assessments.

\section{DNA observations}

All wolves within a territory are assumed to have equal chance to end up in the DNA sample. Sampling is conducted with replacement and getting sampled is assumed to not affect the future chance of getting sampled. Under these assumptions the likelihood function for the number of wolves in a territory given the number of successful samples collected and the number of different individuals found is proportional to a multinomial distribution (Miller et al, 2005). Dropping constant terms yields the following likelihood for the number of wolves in territory $t$ in autumn 


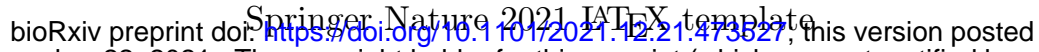
December 22, 2021. The copyright holder for this preprint (which was not certified by peer review) is the author/funder. All rights reserved. No reuse allowed without permission.

$L\left(N_{t}^{(A)} \mid r_{t}^{(A)}+r_{t}^{(S)}, k_{t}^{(A)}+k_{t}^{(S)}\right) \propto \frac{N_{t}^{(A)} !}{\left(N_{t}^{(A)}-\left(r_{t}^{(A)}+r_{t}^{(S)}\right)\right) !}\left(\frac{1}{N_{t}^{(A)}}\right)^{k_{t}^{(A)}+k_{t}^{(S)}}$

where $r_{t}^{(A)}$ and $r_{t}^{(S)}$ are the number of different individuals found in territory $t$ in autumn and in spring, respectively. Number of successful DNA samples collected in autumn and spring are denoted $k_{t}^{(A)}$ and $k_{t}^{(S)}$. The spring samples are added to autumn samples, because any pack member alive in spring must have been a pack member also in previous autumn. The likelihood for the number of wolves in a territory in spring depends only on the samples collected in spring:

$$
L\left(N_{t}^{(S)} \mid r_{t}^{(S)}, k_{t}^{(S)}\right) \propto \frac{N_{t}^{(S)} !}{\left(N_{t}^{(S)}-r_{t}^{(S)}\right) !}\left(\frac{1}{N_{t}^{(S)}}\right)^{k_{t}^{(S)}}
$$

\section{Known mortality and dispersal}

Observed number of dead wolves $\left(d_{t}\right)$ in a territory is treated as an interval censored observation about the true number of dead wolves, so that the observed number of dead wolves gives the lower bound for the true number of wolves that died in the territory.

If the last DNA sample of a wolf is found far away from a territory where the other samples where found, then the DNA sample is excluded from the data. This is because the target is to estimate the number of wolves that occupy the territory in spring.

\section{A.2.2 Computation}

The joint posterior distribution of model parameters was approximated using Markov chain Monte Carlo (MCMC) simulation. The simulation was implemented using JAGS version 4.3.0 (Plummer, 2003). Pre-processing of data and post-processing of simulation results was conducted using $\mathrm{R}$ 3.6.0.

The burn-in period of the MCMC simulation for the population assessment was run using two chains for 10000 iterations, after which 1000000 iterations were produced with thinning of 1000 . Convergence of the simulation was assessed using visual inspection of the chains.

\section{References}

Bassi E, Pervan I, Ugarkovic D, et al (2021) Attacks on hunting dogs: the case of wolf-dog interactions in Croatia. European Journal of Wildlife Research 67(1). https://doi.org/\{10.1007/s10344-020-01451-5\} 


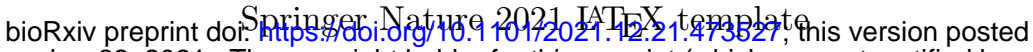
December 22, 2021. The copyright holder for this preprint (which was not certified by peer review) is the author/funder. All rights reserved. No reuse allowed without permission.

Bischof R, Milleret C, Dupont P, et al (2020) Estimating and forecasting spatial population dynamics of apex predators using transnational genetic monitoring. Proceedings of the National Academy of Sciences 117(48):30,531-30,538. https://doi.org/10.1073/pnas.2011383117, URL https://www.pnas.org/content/117/48/30531, https://arxiv.org/abs/ https://www.pnas.org/content/117/48/30531.full.pdf

Bragina EV, Ives AR, Pidgeon AM, et al (2015) Rapid declines of large mammal populations after the collapse of the soviet union. Conservation Biology 29(3):844-853. https://doi.org/https://doi.org/10. 1111/cobi.12450, URL https://conbio.onlinelibrary.wiley.com/doi/abs/10. 1111/cobi.12450, https://arxiv.org/abs/https://conbio.onlinelibrary.wiley. com/doi/pdf/10.1111/cobi.12450

Chapron G, Kaczensky P, Linnell JDC, et al (2014) Recovery of large carnivores in europe\&\#x2019; s modern human-dominated landscapes. Science 346(6216):1517-1519. https://doi.org/10.1126/science.1257553, https: //arxiv.org/abs/https://www.science.org/doi/pdf/10.1126/science.1257553

Chapron G, Wikenros C, Liberg O, et al (2016) Estimating wolf (canis lupus) population size from number of packs and an individual based model. Ecological Modelling 339:33-44. https://doi.org/https://doi.org/10.1016/j. ecolmodel.2016.08.012

Cretois B, Linnell JD, Grainger M, et al (2020) Hunters as citizen scientists: Contributions to biodiversity monitoring in europe. Global Ecology and Conservation 23:e01,077. https://doi.org/https://doi.org/10.1016/ j.gecco.2020.e01077, URL https://www.sciencedirect.com/science/article/ pii/S2351989420303632

Flykt A, Johansson M, Karlsson J, et al (2013) Fear of wolves and bears: Physiological responses and negative associations in a swedish sample. Human Dimensions of Wildlife 18(6):416-434. https://doi.org/10.1080/10871209. 2013.810314, URL https://doi.org/10.1080/10871209.2013.810314, https:// arxiv.org/abs/https://doi.org/10.1080/10871209.2013.810314

Fuller TK, Mech LD, Cochrane JF (2003) Wolf population dynamics. In: Mech LD, Boitani L (eds) Wolves. Behavior, ecology, and conservation. University of Chicago Press, Chicago, p 35-65

Heikkinen S, Valtonen M, Härkälä A, et al (2021) Susikanta Suomessa maaliskuussa 2021. Luonnonvara- ja biotalouden tutkimus 39/2021, Luonnonvarakeskus, Helsinki

Herfindal I, Linnell JDC, Odden J, et al (2005) Prey density, environmental productivity and home-range size in the eurasian lynx (lynx lynx). Journal of Zoology 265:63-71 



December 22, 2021. The copyright holder for this preprint (which was not certified by peer review) is the author/funder. All rights reserved. No reuse allowed without permission.

Jiménez J, García EJ, Llaneza L, et al (2016) Multimethod, multistate bayesian hierarchical modeling approach for use in regional monitoring of wolves. Conservation Biology 30(4):883-893. https://doi.org/ https://doi.org/10.1111/cobi.12685, https://arxiv.org/abs/https://conbio. onlinelibrary.wiley.com/doi/pdf/10.1111/cobi.12685

Johansson M, Sandstrom C, Pedersen E, et al (2016) Factors governing human fear of wolves: moderating effects of geographical location and standpoint on protected nature. EUROPEAN JOURNAL OF WILDLIFE RESEARCH 62(6):749-760. https://doi.org/\{10.1007/s10344-016-1054-5\}

Kindberg J, Swenson JE, Ericsson G, et al (2011) Estimating population size and trends of the Swedish brown bear Ursus arctos population. Wildlife Biology 17(2):114 - 123. https://doi.org/10.2981/10-100, URL https://doi. org $/ 10.2981 / 10-100$

Kojola I, Heikkinen S, Holmala K (2018) Balancing costs and confidence: volunteer-provided point observations, GPS telemetry and the genetic monitoring of Finland's wolves. Mammal Research 63:415-423. https://doi.org/ 10.1007/s13364-018-0371-3

Kojola I, Kaartinen S, Hakala A, et al (2009) Dispersal Behavior and the Connectivity Between Wolf Populations in Northern Europe. Journal of Wildlife Management 73(3):309-313. https://doi.org/\{10.2193/2007-539\}

Liberg O, Chapron G, Wabakken P, et al (2012) Shoot, shovel and shut up: cryptic poaching slows restoration of a large carnivore in europe. Proceedings of the Royal Society B: Biological Sciences 279(1730):910-915. https://doi.org/10.1098/rspb.2011.1275, URL https://royalsocietypublishing.org/doi/abs/10.1098/rspb.2011.1275, https://arxiv.org/abs/https://royalsocietypublishing.org/doi/pdf/10.1098/ rspb.2011.1275

Liberg O, Suutarinen J, Åkesson M, et al (2020) Poaching-related disappearance rate of wolves in sweden was positively related to population size and negatively to legal culling. Biological Conservation 243:108,456. https://doi.org/https://doi.org/10.1016/j.biocon.2020.108456, URL https: //www.sciencedirect.com/science/article/pii/S0006320719311498

Liukko UM, Henttonen H, Kauhala K, et al (2019) Mammals. In: Hyvärinen E, Juslén A, Kemppainen E, et al (eds) The 2019 Red List of Finnish Species. Ministry of the Environment and Finnish Environment Institute, Helsinki, p $571-576$

Luomaranta A, Aalto J, Jylhä K (2019) Snow cover trends in finland over 1961-2014 based on gridded snow depth observations. International Journal of Climatology 39(7):3147-3159. https://doi.org/https://doi. 


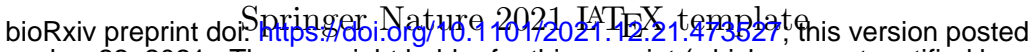
December 22, 2021. The copyright holder for this preprint (which was not certified by peer review) is the author/funder. All rights reserved. No reuse allowed without permission.

org/10.1002/joc.6007, URL https://rmets.onlinelibrary.wiley.com/doi/abs/ 10.1002/joc.6007, https://arxiv.org/abs/https://rmets.onlinelibrary.wiley. com/doi/pdf/10.1002/joc.6007

Mäntyniemi SHP, Whitlock RE, Perälä TA, et al (2015) General state-space population dynamics model for Bayesian stock assessment. ICES Journal of Marine Science 72(8):2209-2222. https://doi.org/10.1093/icesjms/fsv117, URL https://doi.org/10.1093/icesjms/fsv117, https://arxiv.org/abs/https: //academic.oup.com/icesjms/article-pdf/72/8/2209/31227503/fsv117.pdf

Marucco F, Boitani L (2012) Wolf population monitoring and livestock depredation preventive measures in Europe. HYSTRIX-ITALIAN JOURNAL OF MAMMALOGY 23(1):1-4. https://doi.org/\{10.4404/hystrix-23.1-6364\}

Mattisson J, Sand H, Wabakken P, et al (2013) Home range size variation in a recovering wolf population: evaluating the effect of environmental, demographic, and social factors. Oecologia 173(3):813-825. https://doi.org/ 10 . $1007 /$ s00442-013-2668-x\}

Miller CR, Joyce P, Waits LP (2005) A new method for estimating the size of small populations from genetic mark-recapture data. Molecular Ecology 14(7):1991-2005. https://doi.org/https://doi.org/ 10.1111/j.1365-294X.2005.02577.x, URL https://onlinelibrary.wiley.com/ doi/abs/10.1111/j.1365-294X.2005.02577.x, https://arxiv.org/abs/https:// onlinelibrary.wiley.com/doi/pdf/10.1111/j.1365-294X.2005.02577.x

Ministry of Agriculture and Forestry (2019) Management plan for the wolf population in Finland. Publications of the Ministry of Agriculture and Forestry 2019:26, Ministry of Agriculture and Forestry, Helsinki, URL https://julkaisut.valtioneuvosto.fi/bitstream/handle/10024/ 161867/MMM_2019_26.pdf

Mykrä S, Pohja-Mykrä M, Vuorisalo T (2017) Hunters' attitudes matter: diverging bear and wolf population trajectories in Finland in the late nineteenth century and today. EUROPEAN JOURNAL OF WILDLIFE RESEARCH 63(5). https://doi.org/\{10.1007/s10344-017-1134-1\}

Nowak S, Żmihorski M, Figura M, et al (2021) The illegal shooting and snaring of legally protected wolves in poland. Biological Conservation 264:109,367. https://doi.org/https://doi.org/10.1016/j.biocon.2021.109367, URL https: //www.sciencedirect.com/science/article/pii/S0006320721004195

Olson ER, Van Deelen TR, Wydeven AP, et al (2019) A landscape of overlapping risks for wolf-human conflict in Wisconsin, USA. JOURNAL OF ENVIRONMENTAL MANAGEMENT 248. https://doi.org/\{10.1016/ j.jenvman.2019.109307\} 


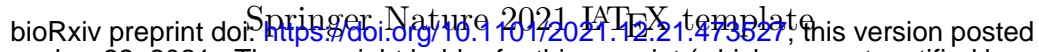
December 22, 2021. The copyright holder for this preprint (which was not certified by peer review) is the author/funder. All rights reserved. No reuse allowed without permission.

Assessment of the Finnish wolf population

Plummer M (2003) JAGS: A program for analysis of bayesian graphical models using gibbs sampling. In: 3rd International Workshop on Distributed Statistical Computing (DSC 2003)

Pohja-Mykrä M, Kurki S (2014) Strong community support for illegal killing challenges wolf management. European Journal of Wildlife Research 60(5):759-770. https://doi.org/https://doi.org/10.1007/s10344-014-0845-9

Punt AE, Smith DC, Smith ADM (2011) Among-stock comparisons for improving stock assessments of data-poor stocks: the "Robin Hood" approach. ICES Journal of Marine Science 68(5):972-981. https://doi. org/10.1093/icesjms/fsr039, URL https://doi.org/10.1093/icesjms/fsr039, https://arxiv.org/abs/https://academic.oup.com/icesjms/article-pdf/68/ 5/972/29140110/fsr039.pdf

Raisanen J, Eklund J (2012) 21st Century changes in snow climate in Northern Europe: a high-resolution view from ENSEMBLES regional climate models. CLIMATE DYNAMICS 38(11-12):2575-2591. https://doi.org/ $\{10$. 1007/s00382-011-1076-3\}

Ripple WJ, Estes JA, Beschta RL, et al (2014) Status and ecological effects of the world\&\#x2019;s largest carnivores. Science 343(6167):1241,484. https: //doi.org/10.1126/science.1241484, URL https://www.science.org/doi/abs/ 10.1126/science.1241484, https://arxiv.org/abs/https://www.science.org/ doi/pdf/10.1126/science.1241484

Suutarinen J, Kojola I (2017) Poaching regulates the legally hunted wolf population in finland. Biological Conservation 215:11-18. https:// doi.org/https://doi.org/10.1016/j.biocon.2017.08.031, URL https://www. sciencedirect.com/science/article/pii/S0006320717302148

Tikkunen M, Kojola I (2020) Does public information about wolf (Canis lupus) movements decrease wolf attacks on hunting dogs (C. familiaris)? NATURE CONSERVATION-BULGARIA (42):33-49. https://doi.org/ $\{10$. 3897 /natureconservation.42.48314\} 


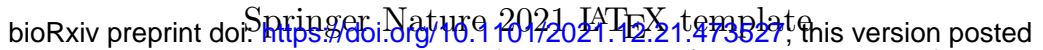

December 22, 2021. The copyright holder for this preprint (which was not certified by peer review) is the author/funder. All rights reserved. No reuse allowed without permission.

22 Assessment of the Finnish wolf population

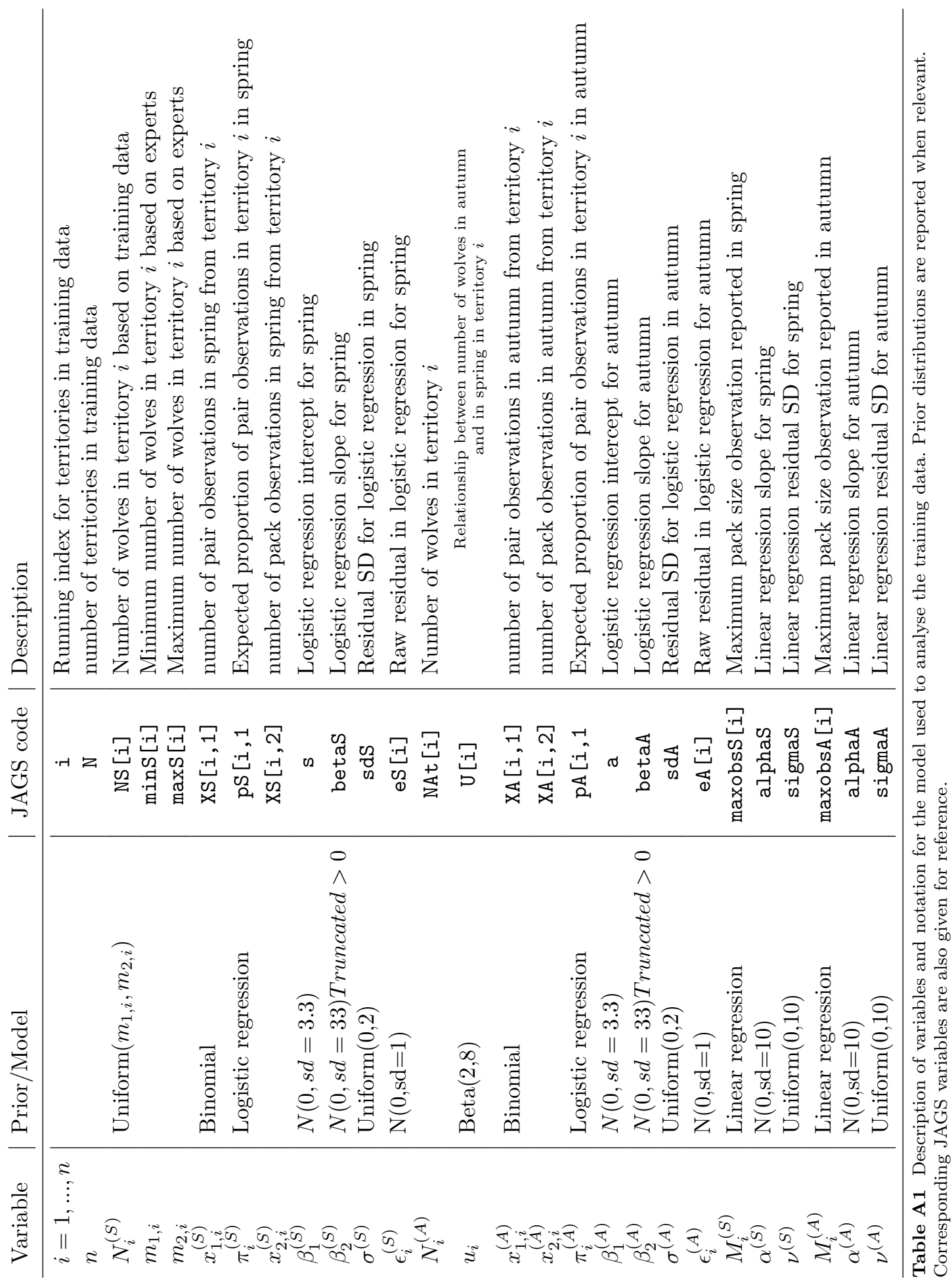




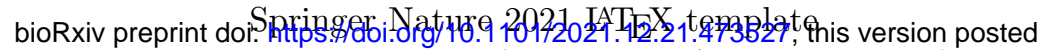

December 22, 2021. The copyright holder for this preprint (which was not certified by peer review) is the author/funder. All rights reserved. No reuse allowed without permission.

Assessment of the Finnish wolf population

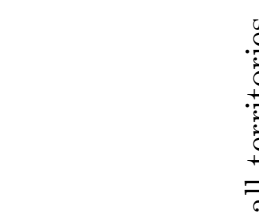

离

苯

$\Xi+\infty . \exists$

(1)

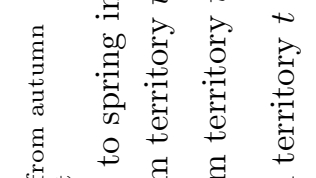

$\Xi$
0

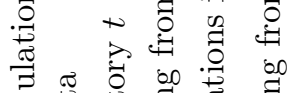

$\stackrel{20}{.7}$

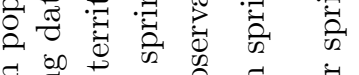



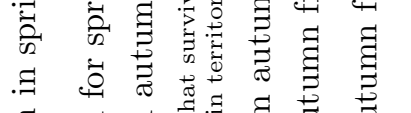

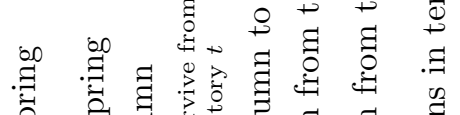

華

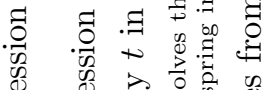

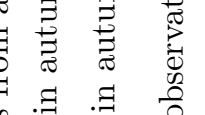

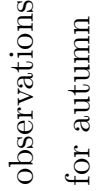

ఏ్ష

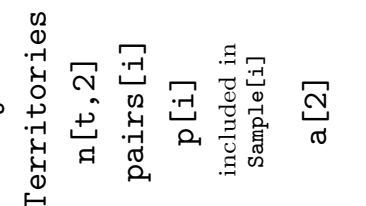

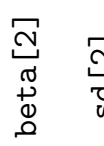

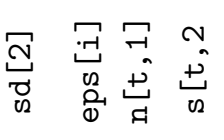

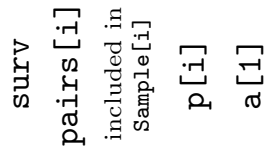

I
$\stackrel{\sigma}{\Xi}$
$\stackrel{0}{0}$
0

壱
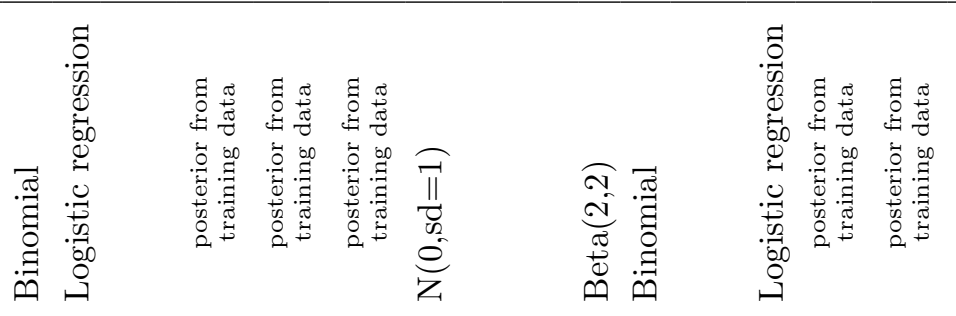

घี

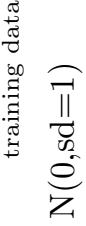

$\frac{\frac{0}{0}}{\frac{\pi}{3}}$

है

-



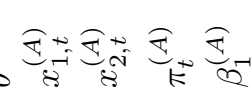




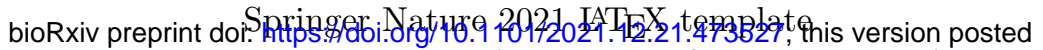

December 22, 2021. The copyright holder for this preprint (which was not certified by peer review) is the author/funder. All rights reserved. No reuse allowed without permission.

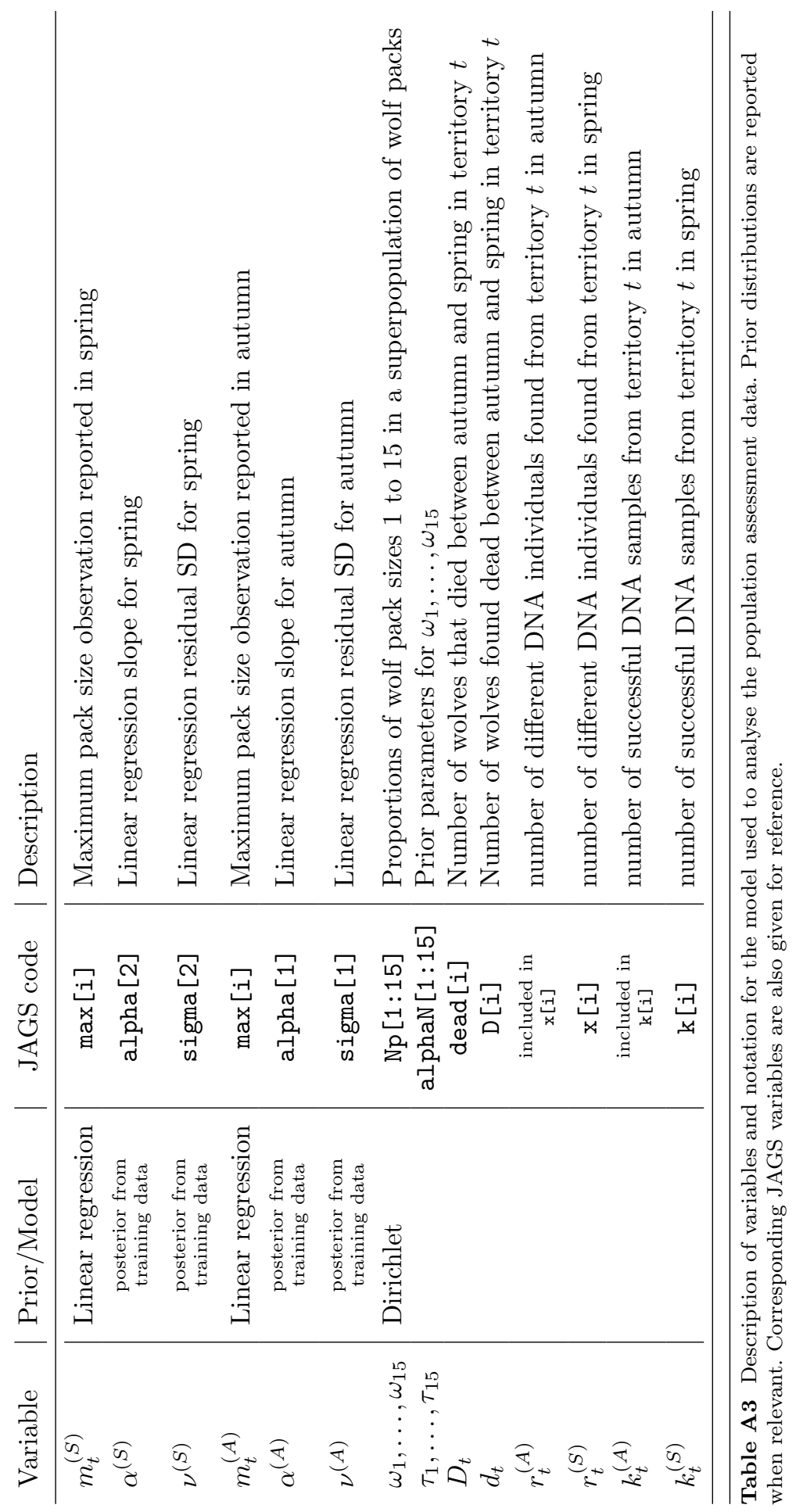

